\title{
O sertão inventado: \\ a percepção dos sertões maranhenses pelo olhar de Francisco de Paula Ribeiro
}

\section{Raimundo Lima dos Santos*}

1. Introdução

Falar sobre o sertão é sempre um ofício prazeroso, especialmente para quem carrega dentro de si, como diria Guimarães Rosa, esse lugar mais que geográfico. Trata-se de tarefa menos elementar do que pode parecer à primeira vista. Um dos motivos para isso é o fato de esse lugar ser um universo de possibilidades que pode assumir diferentes configurações, nos campos da percepção espacial e temporal.

De forma mais abreviada, pode-se afiançar que o significado primeiro para sertão apresenta-se como terras distantes e pouco férteis, ${ }^{1}$ podendo indicar, a princípio, um lugar de desconforto e tristeza, além de economicamente ambíguo. Todavia, o contato do estrangeiro - brasileiro ou não - com essa paisagem provoca um conflito interno nesse transeunte do sertão, que se dá no choque entre o pré-julgamento em contato com uma realidade vivida, capaz de se impor.

Portanto, apesar de rico e múltiplo, o sertão é quase sempre condenado a priori. Mas quando "o conquistador vai escrever no corpo do outro e nele traçar sua própria

" Doutorando em História na Universidade Federal de Minas Gerais (UFMG) e bolsista pela Fundação de Amparo a Pesquisa e ao Desenvolvimento Científico e Tecnológico do Maranhão (FAPEMA). E-mail: santoshistoria@hotmail.com

${ }^{1}$ ARRUDA, Gilmar. Cidades e sertões: entre a história e a memória. Bauru, SP: EDUSC, 2000, p. 165. 
história", ${ }^{2}$ sem perceber, seu corpo também sai escrito por esse "outro", que no primeiro momento parece não ter alma nem vida própria.

Há vários tipos de sertão: geográfico ou poético; distante, como o de Euclides da Cunha; ou tão próximo que chega a se fundir com a própria pessoa, onde quer que ela esteja, segundo a perspectiva de Guimarães Rosa. Há sertão inferno, paraíso; há sertão que é Brasil e outro que não é. Simplesmente esse lugar pode ter muitas formas e sentidos, dependendo de quem o observa.

A perspectiva desse trabalho é partir do sertão geografia, com o objetivo de chegar ao mais simbólico, capaz de se impor como força identitária expressiva na percepção de poetas, politicos, artistas e intelectuais. As belezas naturais e sociais desse lugar são facilmente reconhecidas e retratadas por aqueles que vivem, conhecem ou o tem por objeto de estudo ou inspiração poética.

Sabe-se da enorme influência que o espaço geográfico é capaz de exercer sobre as memórias ou a cultura de um povo, visto que esse "é a realidade que dura" e, se os grupos o moldam, também "se dobram e se adaptam a ele". ${ }^{3}$ As especificidades de cada lugar servem de base para a busca de singularidades culturais ou sociais. ${ }^{4}$

Toda cultura emerge e se desenvolve como fruto de adaptações em determinados locais, como assegurou Clifford Geert $z,{ }^{5}$ e se ela é capaz de construir universos de significados variados, por meio de suas práticas sociais, essas mesmas práticas não estão desvinculadas do mundo material.

Sem paisagem não haveria sertão, visto que o elemento geográfico é ferramenta chave para se entender esse lugar

${ }^{2}$ CERTEAU, Michel de. A Escrita da História. 2. ed. Rio de Janeiro: Forense Universitária, 1982, p. 9.

${ }^{3}$ HALBWACHS, Maurice. A Memória Coletiva. São Paulo: Centauro, 2006, p. 170.

${ }^{4}$ ARRUDA, op. cit., p. 163.

${ }^{5}$ GEERTZ, Clifford. A interpretação das culturas. Rio de Janeiro: Guanabara, 1989 , p. 61.

210 Revista de História Regional 16(1): 209-234, Verão, 2011 
como algo singular, ${ }^{6}$ especialmente no sul do Maranhão, do qual não faltam exemplos em variados escritos.

Por meio da paisagem natural nasce e consolida-se uma forte identidade sertaneja maranhense, "formada ao longo do tempo, através de processos inconscientes". ${ }^{7}$ Para Lúcia Lippi Oliveira8 "a valorização da natureza aparece como efeito compensador à debilidade da cultura no Brasil".

Apesar de tal afirmação ser um pouco simplista, é plausivel concordar com parte dela, uma vez que a construção identitária no Maranhão se edifica na exclusão do nativo. Por força de um destino, o sertão nasce e cresce expulsando o índio para a implantação das fazendas de gado. Os "Pastos Bons" - como ficou conhecido o sertão maranhense - passam a ter existência social a partir do instante que surge o gado para consumir esses pastos.

Não apenas o pasto, como também o clima, a vegetação, as águas e todos os elementos geográficos passam a ter um novo sentido, ressignificado pelo colonizador, pelo criador de gado e pelo repovoador; todos a serviço de uma nova organização social. Nesse contexto, o nativo é um dos componentes de maior empecilho na região para o funcionamento dessa engrenagem de povoamento colonial.

Considerado fator de obstrução, o índio foi energicamente combatido nos campos bélico, econômico, cultural e simbólico. Esse último termo é utilizado aqui conforme a concepção bourdieusiana de ser um "poder de constituir o dado pela anunciação, de fazer ver e fazer crer, de confirmar ou de transformar a visão do mundo". ${ }^{9}$ A substancialização desse poder expõe-se nas práticas de muitas tribos, ao contribuir para a destruição de outras e até mesmo das suas próprias.

${ }^{6}$ OLIVEIRA, Lúcia Lippi. A conquista do espaço: sertão e fronteira no pensamento brasileiro. História, ciências, saúde - Manguinhos, Rio de Janeiro, v. 5, n. S, p. 195-235, jul. 1998, p. 203.

${ }^{7}$ HALBWACHS, op. cit., p. 38.

${ }^{8}$ OLIVEIRA, op. cit., p. 204.

${ }^{9}$ BOURDIEU, Pierre. O poder simbólico. 8. ed. Rio de Janeiro: Bertrand Brasil, 2005, p. 14. 
Obviamente o processo de exclusão indígena não se dá apenas no confronto físico, mas também no campo da escrita, que não deixa de ter sua grande parcela de responsabilidade no processo de exclusão. Aqui, faz-se uso da perspectiva de Edward Said, que realizou um estudo sobre "Orientalismo", um conjunto de práticas discursivas que exercem um forte poder de domínio real sobre a outra parte do mundo. Para tentar resumir o conjunto de argumentos apresentados pelo autor ${ }^{10}$ pode-se ilustrar com uma frase: "um homem oriental era primeiro um oriental, e só em segundo lugar um homem". Essa concepção efetuou toda a ordem de exclusões que se percebe atualmente do Ocidente em relação aos orientais. Numa situação análoga, o mesmo aconteceu aos nativos dos sertões maranhenses.

Quem sucede o índio como representante do sertão é o vaqueiro, visto que este foi o responsável pela criação do gado e pela manutenção da fazenda. Por ser a economia sertaneja regida pela criação do gado, não é dificil entender porque o vaqueiro teve tanta importância simbólica, especialmente após as memórias do militar português Francisco de Paula Ribeiro, no início do século XIX, quando da realização de trabalhos para os quais percorreu toda a região a serviço da Capitania do Maranhão.

Algumas ideias têm a eficácia de perdurar por incontáveis gerações, não apenas pelo fato de expressarem um vasto universo de percepções de dificil contestação, mas porque determinadas instituições ou pessoas têm o poder de exercer forte autoridade simbólica sobre gerações presentes e futuras em relação a outras instituições ou pessoas.

A ideia de que o Brasil representava um paraíso natural deve-se em grande parte às impressões deixadas por Pero Vaz de Caminha, há mais de 500 anos. Da mesma maneira, Euclides da Cunha foi capaz de deixar uma das mais expressivas imagens sobre o Brasil sertanejo. Apesar da distância temporal e da diferença de contexto, é possivel afirmar que tanto um como o outro falam por meio de

\footnotetext{
${ }^{10}$ SAID, Edward, W. Orientalismo: o Oriente como invenção do Ocidente. São Paulo: Companhia das Letras, 2007, p. 313.
}

212 Revista de História Regional 16(1): 209-234, Verão, 2011 
instituições, entretanto, se fossem outras pessoas falando do mesmo lugar, certamente as impressões seriam diferentes.

Para isso acontecer, esse indivíduo deve possuir um capital simbólico, construído por meio de alguma instituição e suficientemente expressivo. Por capital simbólico entende-se que ele é "uma propriedade qualquer, percebida pelos agentes sociais cujas categorias de percepção são tais que elas podem entendê-las (percebê-las) e reconhecê-las, atribuindo-lhes valor". ${ }^{11}$

Esse tipo de ideia ou concepção duradoura denominar-se-á aqui de "percepção criadora". Após os escritos memorialísticos de Francisco de Paula Ribeiro sobre os sertões maranhenses, percebe-se certa duração de algumas ideias suas: refere-se aqui, em primeiro plano, aos três dos mais importantes autores que escreveram sobre o sertão cerca de um século mais tarde. A escolha de Parsondas de Carvalho, Carlota Carvalho, irmã desse, e Dunshee de Abranches justifica-se pelo fato de suas abordagens terem certa afinidade.

O sertão pelo olhar de Paula Ribeiro é, também, um sertão paradisíaco, de ampla variedade de vegetação, espécies animais, inúmeros rios e clima agradável que deveria ser mais bem aproveitado no aspecto econômico, sobretudo por meio do gado. Os povos indígenas deveriam incorporar-se à cultura do trabalho e do modo de vida em geral da "civilização" para serem aceitos como seres humanos. O índio é compreendido como uma ameaça ao projeto da Coroa, de criação de fazendas nos sertões maranhenses, que constantemente destruía povoações, matava os habitantes, levava o gado e alimentos. Paula Ribeiro reconhecia que essas práticas eram fruto de injustiças cometidas contra esses habitantes, mas só reconhece sua humanidade pela assimilação cultural.

O sertão Ribeiriano era também o lugar em que se precisava da lei e da ordem. Ele denunciava roubos e mortes que ocorriam muito facilmente sem a menor punição, o que dificultava o bom andamento das povoações sertanejas. Essa ausência governamental também era fruto da distância que

${ }^{11}$ BOURDIEU, op. cit., p. 107. 
isolava a região. A capital da provincia, São Luís, estava fora das rotas terrestres e fluviais. Somente no século XIX começou-se a viajar pelos rios até a capital, sendo que o contato dos sertões acontecia basicamente com o Piauí.

Inicialmente, Pastos Bons era como se denominava toda a parte sul da província. Com o tempo apenas a área que foi transformada em Vila, no ano de 1770, passou a ser chamada assim, quando o rei Dom José I a submeteu à jurisdição de Oeiras, no Piauí, por conta de uma maior proximidade econômica, política e cultural com a cidade. Esse isolamento foi base para uma carga de conflitos com o reforço de que o sertão era diferente do litoral. Essas ideias culminaram com a proposta de separação politica e a criação da república de Pastos Bons, no ano de 1827.

Novos elementos surgiram, inovando as impressões deixadas por Francisco de Paula Ribeiro, a exemplo de uma maior valorização do índio, com denúncias mais veementes das injustiças cometidas contra eles: expulsões, tomadas de terras, escravização, assassinatos. Nesse aspecto, a historiadora Carlota Carvalho deu alguns passos, um século depois de Paula Ribeiro, mas não conseguiu fazer uma leitura que construísse uma identidade indígena associada ao sertão.

Outro novo elemento em relação aos "primeiros escritos sertanejos" é a percepção de que o sertão estaria isolado, devendo não apenas ser anexado ao poder púbico, como queria Paula Ribeiro, mas também conquistar sua própria independência politica. Carlota Carvalho faz uma investigação sobre as lutas pela independência no Brasil e, nos sertões, por meio da Balaiada, movimento eclodido em meados do século XIX com participação de índios, negros, libertos pobres e intelectuais que visava, entre outras medidas, melhores condições de vida para o povo e independência política.

Dunshee de Abranches foi um promotor no sertão à época da Proclamação da República, escreveu suas memórias em 1940, publicadas em 1959 pela primeira vez, nas quais faz uma defesa dessa liberdade politica do sertão. Seu trabalho inicial seria efetuar um levantamento das causas dos conflitos ocorridos entre as duas famílias mais influen-

214 Revista de História Regional 16(1): 209-234, Verão, 2011 
tes do sertão, região de Grajaú, uma conservadora e outra liberal. Com o tempo aderiu à causa dos republicanos e se decepcionou ao ver os conservadores continuarem no poder mesmo após a Proclamação da República.

Parsondas de Carvalho deu uma imensa contribuição ao retratar o quadro de violência que viveu o sertão, num famoso conflito entre famílias conhecido por "Guerra dos Leda", o qual provocou muitas mortes e espalhou o temor pela região. "Tão frequentes se tornaram as questões no Grajaú e tal aspecto apresentava, que deixavam formar-se a idéia contristadora dessa localidade está quase em estado de selvageria". ${ }^{12}$ Publicou diversos artigos nos jornais $\mathrm{A} \mathrm{Pa}$ cotilha, da capital, e no Jornal do Brasil, do Rio de Janeiro, nos quais denunciou o clima de instabilidade politica em que vivia o sertão.

Mesmo quando parecia que a paz reinaria, Parsondas afirmou no A Pacotilha, em 1902, que "não conheço, dentro da Constituição de 24 de fevereiro, meio algum para o governo federal garantir o cidadão contra a tirania dos governos estaduais". ${ }^{13}$ Sua visão de alguma forma contribuiu com o sentimento de que o sertão é um lugar que necessitava da ordem e da liberdade para fazer sua própria organização.

\section{O nascimento do sertão}

A aurora colonizadora sertaneja maranhense tem origem na região baiana, no momento em que suas fazendas, por necessidades econômicas e sociais, começam a dilatar-se em direção ao interior. Tanto aquela capitania como a de Pernambuco, no século XVII, eram os principais centros açucareiros do país. Essas duas áreas econômicas dilatam-se em

${ }^{12}$ CARVAlHO, Parsondas. A Amazônia: do Gurupi ao Balsas. Conferência feito pelo Sr. João Parsondas de Carvalho na Sociedade de Geografia do Rio de Janeiro, em 24 de dezembro de 1901. In: DINO, Sálvio. Parsondas de Carvalho: um novo olhar sobre o sertão. Imperatriz, MA: Ética, 2007, p. 143.

${ }^{13}$ Ibidem, p. 195. 
direção às regiões intituladas por Capistrano de Abreu como os "sertões de dentro e sertões de fora". ${ }^{14}$

A ocupação dos "sertões de fora" foi liderada pela capitania de Pernambuco e, como o próprio termo indica, ficou mais restrita às áreas litorâneas que interioranas. Teve papel importante ao desempenhar a função de abastecer o mercado das minas. ${ }^{15}$ Essa frente ocupou inicialmente a região que corresponderia à Paraíba e ao Rio Grande do Norte, expandindo-se em seguida pelo interior. ${ }^{16}$ Posteriormente, foi responsável por grande parte da ocupação da costa nordestina, como no caso da capitania do Ceará.

No que se refere à ocupação dos "sertões de dentro", na Bahia, Francisco Dias d'Ávila, um grande proprietário de terras, fez novo requerimento de sesmarias a fim de aumentar suas posses e prestígio social. "Como seus gados não davam para encher tamanhas extensões, arrendava sítios, geralmente de uma légua". ${ }^{17}$

Para Capistrano de Abreu, ${ }^{18}$ o início da criação do gado surge na cidade de Salvador, posteriormente estendendo-se à margem direita do São Francisco. O mercado de carnes tinha força significativa nesse período, pois basicamente era o único centro abastecedor da colônia. À medida que a demanda crescia, as fazendas expandiam-se rio adiante.

A partir de 1730, as primeiras fazendas de gado começaram a se instalar no sul do Maranhão, tendo como uma das principais circunstâncias a demanda de carne na região das Minas Gerais. Uma década mais adiante, fundou-se o povoado de Pastos Bons, centro de gravidade da ocupação sul maranhense. Pouco tempo após a fundação, já havia nos sertões 44 fazendas.

\footnotetext{
${ }_{14}$ ABREU, J. Capistrano de. Capitulos de história colonial: (1500-1800). 5. ed. rev., anotada e pref. por José Honório Rodrigues. [Rio de Janeiro?]: Soc. Capistrano de Abreu; Briguiet, 1969, p. 164.

${ }^{15}$ CABRAL, Maria do Socorro Coelho. Caminhos do gado: conquista e ocupação do sul do Maranhão. São Luís: Edições SECMA, 1992, p. 102.

${ }^{16}$ PRADO Jr, Caio. Formação do Brasil Contemporâneo: Colônia. São Paulo: Brasiliense, 2006, p. 62-3.

${ }^{17}$ ABREU, op. cit., p. 160.

${ }^{18}$ Ibidem, p. 157.

216 Revista de História Regional 16(1): 209-234, Verão, 2011
} 
Essa região conheceu uma era de ouro na pecuária, que se deu tanto por conta de fatores exógenos, no que tange à demanda de carne para outras regiões e a expansão de empreendimentos açucareiros, quanto por fatores endógenos, com excelentes condições naturais que a região possuía para essa empresa: clima, relevo pouco acidentado, grande quantidade de água disponível nos seus rios e, principalmente, os pastos naturais existentes de boa qualidade, suficientes para batizar o lugar com o nome de "Pastos Bons". Caio Prado Júnior descreveu as condições para a criação do gado nos sertões:

Constitui-se de largos chapadões de terreno mais ou menos unido e plano; e a vegetação, ao contrário das densas matas que bordam boa parte do litoral e revestem outras áreas do território da colônia, é formada de uma associação florística que, sem ser rasteira, é bastante rala para oferecer passagem natural franca, dispensando para a instalação do homem quaisquer trabalhos preliminares de desbravamento ou preparo do terreno $[\ldots] .{ }^{19}$

Outro componente considerável foi o fato de o gado dar-se bem numa região imprópria ao cultivo da cana. Isso criou uma combinação ideal, à medida que não houve choque entre os dois empreendimentos. Pelo contrário, existiu uma simetria ao demandarem geografias diferentes e uso de pouca mão de obra na pecuária. "Condição de alta valia num país de população rala". ${ }^{20}$

Pela Ordem Régia de 1695, o tamanho das fazendas foi delimitado em três léguas em média, separadas normalmente por um rio que fracionava a propriedade em três quilômetros para cada margem. ${ }^{21}$ Apesar de toda essa extensão, via de regra, só um vaqueiro era necessário na administração da fazenda, que contava com a colaboração de um ou dois auxiliares cognominados "fábricas".

Durante algum tempo, a região de Pastos Bons abaste-

\footnotetext{
${ }^{19}$ PRADO Jr, op. cit., p. 62.

${ }^{20}$ ABREU, op. cit., p. 157.

${ }^{21}$ PRADO Jr, op. cit., p. 192.
} 
ceu mercados em outras regiões, todavia, a pecuária nordestina começou a dar sinais de decadência a partir do final do século XVIII, com a ascensão da mesma atividade mineira e sulista. Em Minas Gerais, as condições naturais e técnicas eram significativamente favoráveis.

Mediante o desenvolvimento de uma agricultura local em Minas, foi possivel auxiliar na alimentação do gado ao proporcionar um alargamento na qualidade. Essa região fez uso de trabalho escravo, de forma a tornar mais favorável um acompanhamento e controle de crescimento do rebanho em termos não apenas quantitativos.

A partir dessas condições indicadas, foi possivel um desenvolvimento da indústria e comércio de produtos derivados do leite, especialmente o queijo, o que não aconteceu, de igual forma, na pecuária maranhense.

Outra região de grande crescimento pecuário foi o Rio Grande do Sul, que, embora não tenha desenvolvido as mesmas qualidades técnicas que Minas, tornou-se um grande exportador nacional de carne, especialmente na forma de charque, graças às suas condições naturais de clima e às suas pastagens.

Nesse processo de fluxo e refluxo pecuário, a região de Pastos Bons sofreu certo retraimento econômico, evidenciando seu isolamento geográfico e político. Medidas foram tomadas visando suavizar a situação:

[...] em 1770 Pastos Bons foi visitada por um governador maranhense. Demonstrou empenho para incorporar Pastos Bons à dinâmica da vida social, econômica e política do Maranhão litorâneo. Abriram uma estrada ligando os sertões à Baixada $[\ldots]^{22}$

No mesmo ano, Pastos Bons foi elevada à categoria de Vila e, por conta do distanciamento da capital, submeteu-se à jurisdição da cidade de Oeiras, por estar mais ligada política, econômica e culturalmente à cidade piauiense do que a

${ }^{22}$ COELHO, Celso Barros (Coord.). Memórias de Pastos Bons. Imperatriz, MA: Ética, 2005, p. 25.

218 Revista de História Regional 16(1): 209-234, Verão, 2011 
São Luís. Incentivou-se a navegação por alguns rios como o Itapecuru e o Tocantins, a fim de melhorar as comunicações, e foram criadas ou emancipadas outras povoações pertencentes a Pastos Bons. O objetivo seria favorecer a administração política e econômica. Sem dúvida o vínculo com o norte da capitania melhorou visivelmente nas diversas esferas, ainda assim, não foi suficiente para conter um persistente sentimento de autonomia em relação ao norte.

\section{Algumas considerações sobre Francisco de Paula Ribeiro}

As informações existentes sobre o português Francisco de Paula Ribeiro são escassas, exceção feita às notícias referentes ao seu tempo de serviço prestado na capitania do Maranhão. Sabe-se que, quando da sua chegada de Portugal nos últimos anos do século XVIII, ele ainda era um jovem militar sem patente importante. Conseguiu alcançar o posto de major efetivo pelos serviços prestados à Coroa num período de cerca de 20 anos.

Sempre foi um convicto defensor dos interesses da Corte portuguesa até o dia de sua morte, em 1823, no interior dos sertões à beira do rio Balsas. Desempenhou um trabalho que foi além das exigências formais de sua função, e só o fez porque se considerava um missionário do desenvolvimento em beneficio da capitania e, fundamentalmente, da Coroa. Tamanho empenho lhe dava direito de, às vezes, fazer reclamações sutis em relação ao reconhecimento de seus esforços:

Há homens que, instalados somente do seu espírito patriótico (o que é muito raro), entram em planos e se arrojam a descobertas que, se elas se utilizassem, dariam um grande nome aos Estados, mas sucede infelizmente que, quase sempre abandonados, as suas forças débeis por isso não podem chegar à meta sublime e fisica a que suas vantajosas idéias 
se propõem, ficando por isso sendo, como se o não fossem, tão generosos esforços $[\ldots]^{23}$

Certamente Paula Ribeiro refere-se aos seus próprios esforços, de maneira aparentemente despretensiosa, mas diante da importância que julgava ter seu trabalho não poderia deixar de fazer críticas. Participou diretamente da abertura de estradas no sertão, da ampliação de parte da navegação fluvial em diversos pontos estratégicos da região e, sobretudo, teve participação considerável na fundação de povoações importantes. ${ }^{24}$

Não se deve deixar de expor suas contribuições na delimitação de fronteiras entre as capitanias do Maranhão e Goiás. Refere-se, em primeiro plano, à cidade de São Pedro de Alcântara, posteriormente Carolina, que foi fundada em 1810 e anexada à jurisdição goiana, passando ao domínio maranhense após o trabalho de demarcação dos limites entre as capitanias, realizado por Paula Ribeiro, no ano de 1815.

De igual forma, não se deve invalidar as contribuições à Coroa no aspecto econômico, pois ele fez um detalhado mapeamento das potencialidades socioeconômicas dos sertões. Chegou à conclusão de que a região poderia, caso assistida econômica e politicamente pelos governantes, tornar-se um grande centro econômico regional e, mesmo, nacional.

Francisco de Paula Ribeiro é adepto do pensamento ilustrado. Essas ideias estão relacionadas a um novo formato de colonização, ainda que com os mesmos principios motores. Para expressar de maneira sucinta, esse modelo surgiu com o desejo de conceder algumas vantagens e privilégios às colônias, para consolidar, por outro lado, o pacto colonial.

\footnotetext{
${ }^{23}$ RIBEIRO, Francisco de Paula. Roteiro da viagem que fez o capitão Francisco de Paula Ribeiro às fronteiras da Capitania do Maranhão e da de Goiás no ano de 1815 em serviço de S.M. Fidelíssima. In: FRANKLIN, Adalberto; CARVALHO, João Renôr F. de. Francisco de Paula Ribeiro: desbravador dos sertões de Pastos Bons: a base geográfica e humana do sul do Maranhão. Imperatriz, MA: Ética, 2005, p. 83.

${ }^{24}$ RIBEIRO, Francisco de Paula. Memórias dos sertões maranhenses. Reunidas aos cuidados de Manoel de Jesus Barros Martins. São Paulo: Editora Siciliano, 2002, p. 10.

220 Revista de História Regional 16(1): 209-234, Verão, 2011
} 
Para Fernando Novais, ${ }^{25}$ foi no período de D. Maria I e do príncipe Dom João que Portugal incorporou essas ideias com mais vigor, por volta do final do século XVIII. Com bases mais "racionais" procuraram otimizar ao máximo as riquezas coloniais e, para tanto, seria necessário conhecer melhor as colônias. Um conjunto de memórias econômicas foi elaborado com a intenção de aprimorar o conhecimento técnico e científico de forma mais utilitária. O primeiro passo de uma Nação "[...] é conhecer as terras que habita, o que em si encerram, o que de si produzem, e o de que são capazes". ${ }^{26}$ As memórias de Paula Ribeiro estão inseridas nesse contexto utilitário metropolitano.

Para o Bispo Azeredo Coutinho, a metrópole seria uma mãe para as colônias. Como as mães tendem a ser possessivas, não é difícil perceber as intenções exclusivistas no âmbito econômico e político. "Por isso que é mãe, deve prestar às colônias suas filhas todos os bons oficios e socorros necessários para a defesa e segurança das suas vidas e dos seus bens, mantendo-se em uma sossegada posse e fruição dessas mesmas vidas e desses bens". ${ }^{27}$

Nessa perspectiva é que o trabalho de Paula Ribeiro foi solicitado aos sertões maranhenses. Além dos trabalhos indicados aqui anteriormente, ele foi convocado para contribuir na criação de Fazendas Reais, com especificidade no gado vacum. "Três fazendas seriam criadas para o fornecimento de matrizes em criações de novas fazendas na região". ${ }^{28}$

$\mathrm{Na}$ realização do trabalho confrontou algumas tribos indigenas arredias a esse modelo socioeconômico. Pastos Bons era considerado um ponto fundamental para o desenvolvimento regional e o nativo foi, na maior parte das vezes, seu inimigo. Paula Ribeiro encontrava nesse projeto não apenas uma "salvação" econômica, mas uma "salvação" cultural:

\footnotetext{
${ }^{25}$ NOVAIS, Fernando A. Portugal e Brasil na Crise do Antigo Sistema Colonial (1777-1808). São Paulo: HUCITEC, 2001, p. 224.

${ }^{26}$ Ibidem, p. 225.

${ }^{27}$ Ibidem, p. 230-1.

${ }^{28}$ RIBEIRO (2002), op. cit., p. 16.
} 
Se por uma parte aproveitamos tantos povos, que talvez por fim se venham a domesticar-se e tornar-se sociais e colonos úteis; por outro lado, se não for coibido a barbaridade de seus naturais insultos também perderemos, e talvez com maior perigo um grande número de famílias coloniais, de que muitos virão a ser abastados lavradores. ${ }^{29}$

Mesmo que para esse "processo civilizatório" fosse necessário utilizar a força. No final da segunda década do século XIX, Paula Ribeiro andou por vários lugares no sertão à procura das melhores localizações para a implantação das fazendas. Um dos objetivos dessa empreitada era amenizar uma longa crise politica e econômica que a capitania enfrentava.

Desde a ocupação do sertão de Pastos Bons é visivel a ausência do poder público, pois os governos provinciais estiveram, de maneira geral, voltados aos problemas do litoral. Apesar disso, houve tentativas, em meados do século XVIII, de organizar expedições em rios importantes, com o interesse de aproximar o sertão à capital. Paula Ribeiro aderiu essa causa de "salvar" os sertões de Pastos Bons do isolamento e abandonado.

\section{O sertão geografia}

Em suas memórias, Paula Ribeiro se esforça para não expressar suas angústias pessoais, seus espantos, medos, dificuldades, porque, como um bom militante da causa portuguesa, tem um profundo interesse em apresentar o máximo de resultados possiveis com o mínimo de empecilhos. Procura, em sua escrita, como manda o protocolo, um estilo racional, de forte teor econômico e propositivo de mudanças para os sertões e para a Coroa. Apesar disso, Ribeiro não poderia deixar de ser humano e expressar sua visão de mundo. Nesses sentimentos expressos pelo viajante, encontram-se as percepções criadoras de um olhar que ainda transpira na

${ }^{29}$ RIBEIRO (2005), op. cit., p. 38.

222 Revista de História Regional 16(1): 209-234, Verão, 2011 
escrita de historiadores, poetas ou quaisquer outros que escrevam sobre o sertão maranhense.

Uma das primeiras observações de Paula Ribeiro em relação à geografia se refere às suas águas: rios e riachos. Essa região possui uma imensidade de cursos d'água, rios importantes que cruzam-na por inteiro ao longo das fronteiras e pelo interior. Tais rios, durante boa parte da história sertaneja, serviram quase exclusivamente como as vias trafegáveis, visto que as estradas terrestres eram basicamente inexistentes.

Viajou, conheceu e bebeu a água desses rios, a exemplo do rio das Balsas, rio Tocantins, rio Grajaú, Itapecuru, Manoel Alves Grande e Mearim. Esses chamavam a atenção não apenas pelo potencial em navegação, mas pelas outras possibilidades econômicas e políticas: pelo favorecimento na criação de gado; pela qualidade apresentada ao consumo humano; por serem "águas saborosíssimas", como as do rio Balsas; e por serem rios que abundavam em peixes, conforme afirmava em suas alusões ao Manoel Alves Grande.

$\mathrm{O}$ autor referiu-se ao clima de Pastos Bons, ao dizer que era bastante favorável à criação do gado, que só não se multiplica mais rapidamente em consequência da "abominável prática dos fazendeiros em venderem ou matarem as vacas para o consumo", em vez de os machos. Relata que o clima da região seria um ambiente ideal, melhor que o da Europa que é frio em demasia, sem ser caloroso a ponto de trazer incômodos aos animais e habitantes do lugar. Num tom levemente romântico diz: "o clima do país, não só amigo do seu habitador, tanto que em toda a capitania encontrei homens tão velhos sendo trivial entre eles a idade de cem anos". ${ }^{30}$

Ao falar sobre o solo, descreve-o como possuidor de uma diversidade expressiva de caças, suficiente para sustentar as populações mais pobres. Esse solo seria também capaz de oferecer os melhores frutos que se poder colher, dentre os quais cita, em especial, a laranja, a guabiroba e as mangabas.

${ }^{30}$ RIBEIRO (2005), op. cit., p. 118. 
Dessa última, diz que por serem tão deliciosas "são dignas até da mesa de um príncipe". ${ }^{31}$

Há vários momentos de admiração com as riquezas naturais existentes no sertão, capazes de despertar impressões poéticas até mesmo em um "militar ilustrado". Pode-se observar, de forma sucinta, o que era aquele sertão geográfico para o ainda capitão português:

A natureza de uns e de outros terrenos, excessivamente pródiga na sua vegetação, é que talvez adquiriu para todo este distrito o nome de Pastos Bons. Os seus campos nutridores, o seu ar cômodo, preciosas águas, grande fertilidade seguida ao mais pequeno cultivo e a sua nunca interrompida verdura, são circunstâncias que fazem com que este país seja o mais abundante e delicioso $[\ldots]^{32}$

Certamente essa parte das descrições memorialistas é a mais poética. Seria muito dificil para um homem acostumado às paisagens europeias entrar em contato com cenários tão paradisíacos e não sofrer um conflito, no qual o misto de admiração e rejeição procuraria harmonizar-se na cabeça e no coração daquele desbravador.

\section{O sertão economia}

Nos escritos mais utilitaristas, Paula Ribeiro deixa menos margem às pinceladas poéticas e pessoais. Seu papel é rigorosamente cumprido: conhecer, desbravar, descrever e conquistar, sob novas perspectivas. Ainda assim entra um elemento que foge um pouco ao primeiro propósito do trabalho e do próprio autor, a saber, o isolamento do sertão.

Evidentemente, quando Paula Ribeiro fala de isolamento está se referindo, em primeiro plano, ao aspecto estritamente comercial e jurídico, só em seguida, vem o aspecto político. Tanto um como o outro são vistos pelo olhar da tutela, do controle Real, da liberdade aprisionada. Não obstante, isso

${ }^{31}$ RIBEIRO (2005), op. cit., p. 155.

${ }^{32}$ Ibidem, p. 151.

224 Revista de História Regional 16(1): 209-234, Verão, 2011 
acabou por contribuir, de alguma maneira, para despertar um olhar mais amplo em relação à liberdade nos sertões.

Ao analisar uma região localizada nas proximidades do rio Alpercatas, próxima a Vila de Caxias, ele afirmou ser aquela região detentora de excelentes condições para o cultivo agrícola. Mais que isso, reforçou ser aquela área a mais propícia para essa atividade em toda a capitania maranhense. ${ }^{33}$

Em relação à mineração, apesar de não ser objetivo da Coroa naquela região, Paula Ribeiro fez algumas conjecturas a respeito de uma suposta existência de metais preciosos. Para ele, o insucesso na descoberta de metais preciosos se dá por "falta de uma investigação e por pessoas que fossem suscetiveis desses conhecimentos". A não descoberta do ouro poderia estar relacionada também a dificuldades impostas pelos índios Xavantes, que não permitiam a exploração das águas.

O Funcionário Real português julgava os indios mais vítimas do que carrascos nesse processo de embate com o homem branco, chegando inclusive a denunciar atos destrutivos de povoações como reflexo das "maldades cometidas pelos brancos ao longo do tempo". Em grande parte das vezes, as perdas provocadas pelas tribos não são mais que "reflexos de seus ressentimentos". ${ }^{34}$

Uma das principais causas desses ressentimentos tinha origem nas "expedições injustas sobre aqueles desgraçados", que nada mais eram do que empreitadas de aprisionamentos para vendê-los como escravos em outras regiões, como a capitania paraense. Naquele momento, para o tipo de atividade econômica pretendida, a escravidão não fazia muito sentido, o que contribuiu para a crítica dessa prática.

Contudo, não se deve esquecer que esses povos nativos sempre representaram um grande problema para Paula Ribeiro. A condição sine qua non para deixarem de ser obstáculo seria assimilarem um comportamento social adequado às atividades econômicas do empreendimento Real: a fazenda ou a agricultura.

\footnotetext{
${ }^{33}$ RIBEIRO (2005), op. cit., p. 79.

${ }^{34}$ Ibidem, p. 93.
} 
Para a incorporação do nativo à dinâmica da vida econômica regional, diz o militar "que nada haveria mais fácil do que ganhar para o Estado tão sofrivel número de vassalos", ${ }^{35}$ bastando, para isso, tratá-lo de melhor forma. Boa proposta, numa região em que não se encontrava mão de obra tão facilmente, especialmente para a agricultura, pois a principal atividade, a criação de gado, necessitava basicamente de vaqueiros e ajudantes.

Pela responsabilidade do vaqueiro, Paula Ribeiro defende melhores condições de vida para essa categoria. Pode-se complementar que, sem o vaqueiro, não haveria fazenda nos sertões maranhenses. Para esse empreendimento, o militar reivindicava maior assistência governamental, no sentido de integrar a região a outros centros urbanos comerciais e abreviar o isolamento. Uma das propostas de combate a isso era o melhor aproveitamento dos rios como meio de transporte, mais rápido que o trajeto pelos caminhos terrestres.

Segundo Paula Ribeiro, esse distanciamento do poder público em relação ao sertão trazia uma série de prejuízos à criação do gado, constantemente avariada por ataques indígenas. As fazendas estavam destruídas e o problema maior era "a falta de providências e de socorros pelas competentes administrações desse e de outros tempos têm sido causa de tamanhos males". Continuando seus lamentos, diz que o resultado dessa prática histórica provocou "insanáveis prejuízos nos rendimentos da Real Fazenda". ${ }^{36}$

Ainda que o maior responsável por esse conjunto de problemas fosse o próprio "poder central", atribui-se culpa também aos administradores locais que não obedeciam às ordens superiores e que se deixavam absorver por disputas locais e pessoais. Ribeiro era enfático ao reiterar que "parece até que de propósito se tem deixado ir tudo por água abaixo". Outro problema era a ausência militar na região, o que favorecia pessoas de "má índole" que "por pouca coisa matam sem maiores problemas com a justiça".

\footnotetext{
${ }^{35}$ RIBEIRO (2005), op. cit., p. 101.

${ }^{36}$ Ibidem, p. 180.

226 Revista de História Regional 16(1): 209-234, Verão, 2011
} 
Percebe-se por esses apontamentos uma visão de abandono pelo poder público em diferentes esferas. Tais problemas contribuíram com uma cadeia de mobilizações internas no sentido superar esse desprezo, com a reivindicação de melhores condições de sobrevivência. Seu diagnóstico estava correto e, menos de uma década depois, surgiu o movimento vozeando uma república nos sertões de Pastos Bons. Em menos de duas décadas, eclodiria a Balaiada.

Paula Ribeiro jamais cogitou, textualmente, uma autonomia para o sertão: toda liberdade e benefícios econômicos ou políticos deveriam ser tutelados pela "mãe" metrópole. O que mais durou em relação à sua percepção foi a ideia de que o sertão estava desamparado e precisava de assistência digna de sua grandeza. Ainda que a grandeza do seu sertão estivesse mais na geografia que no próprio povo, especialmente o indigena.

\section{O sertão do povo}

Ao se tratar de povo, o sertão ribeiriano é julgado sob a perspectiva de uma hierarquia cultural. Um dos primeiros aspectos que denota essa inferioridade sertaneja é encontrado na ausência de escolas na região. "Não só as primeiras letras e as artes liberais, mas ainda mesmo as mecânicas, lhe são inteiramente desconhecidas". ${ }^{37}$ Esse aspecto da falta de cultura institucionalizada, somado ao modo de vida natural, é visto como algo prejudicial, feio e, principalmente, errado. Muitos no sertão, para ele, são inimigos do trabalho, especialmente os que não assimilam uma vida de trabalho formal.

O europeu se impressionou ao ver grandes fazendeiros no sertão, possuidores de notável quantidade de gado e terra, viverem junto aos pobres, mal vestidos, com alimentação simples, dormida rústica e tudo o mais de um modo de vida sertanejo. Seu espanto o conduz a uma comparação com o que ele considerava mais inferior: "os selvagens".

${ }^{37}$ RIBEIRO (2005), op. cit, p. 117. 
Não obstante, apesar de "rústicos e brutais", sua índole é boa, e só é boa porque suas práticas culturais e sociais não se chocam com as necessidades da criação do gado, elemento fulcral para o sistema econômico do sertão. Ao contrário, sua maneira de ser encaixava-se perfeitamente à realidade da fazenda. Esta não era apenas o local da criação do gado, mas também o lugar da produção de todas as necessidades: alimentos, roupas, instrumentos de trabalho, dentre vários outros produtos.

Mesmo de forma rústica, a fazenda era basicamente autossuficiente em todas as suas necessidades. O próprio fazendeiro era fruto daquele contexto de escassez e rusticidade, por isso, seus defeitos não chegavam a "escandalizar a humanidade", visto serem "hospitaleiros, agasalhadores, e tratam aos passageiros, de que sempre têm concorrência, com aquele agrado próprio sim da sua rusticidade". ${ }^{38}$

Boa medida da antipatia em relação aos índios estava no fato de eles nem sempre serem tão hospitaleiros quanto os outros sertanejos. De modo contrário, o índio constantemente era visto como imprevisivel, temivel e prejudicial às organizações populacionais colonizadoras. Admitia sua "inocente moral", uma vez que após constantes traições e maus tratos diversas tribos continuavam dóceis aos brancos e quase sempre dispostos a servi-los. Nesse ponto, Paula Ribeiro cultivava esperanças de incorporação ao mundo do trabalho institucional por parte dos povos nativos do sertão.

O funcionário da Coroa assegurava que com poucos esforços eles poderiam se tornar úteis a si mesmos, ou melhor, aos interesses reais. Ao referir-se a essa facilidade, toma por base as tribos com que teve contato, especialmente aquelas que o auxiliaram, de alguma maneira, em seus trabalhos no interior do sertão.

Quando a situação tratava de tribos mais distanciadas em termos de relacionamento, o julgamento era motivado por outros princípios. "Estes bárbaros, com cujos chefes tivemos largas conferências, não têm ainda perdido nada do

${ }^{38}$ RIBEIRO (2005), op. cit., p. 117.

228 Revista de História Regional 16(1): 209-234, Verão, 2011 
seu estado e educação brutal", diz Paula Ribeiro, e continua reiterando que, após oito anos de convivência, eles viviam ainda "com a imodesta nudez, a inação e todos os péssimos costumes naturais seus". ${ }^{39}$ Dentre eles, a maneira de prepararem a comida no chão, com pedras em brasas, o desprezo no tocante à religião católica e diversos outros aspectos.

Em nenhum momento dos seus escritos há evidência de que o português tenha aprendido alguma das linguas indígenas durante as duas décadas de trabalho em meio a várias dessas tribos. Enfrentou algumas, expulsando-as, a fim de abrir caminho à implantação de fazendas ou povoações. Também fez várias parcerias com aquelas mais suscetiveis ao contato com o branco.

Não apenas desconheceu seus dialetos, ao que parece, como não conseguiu compreender seus costumes e sua cultura. Para ele, os costumes indigenas pouco se diferenciavam. Interesseiros, suas amizades eram condicionadas por ganhos pessoais, dizia o militar. ${ }^{40}$ Afirmava, ainda, que preferiam viver da caça ao trabalho das grandes culturas e só saiam de seu habitat natural quando "querem roubar as frutas campestres dos outros timbiras, seus vizinhos, ou invadir as nossas fazendas de gado". ${ }^{41}$

Apesar de elogiar o casamento, que se realiza aos 25 anos para os homens e aos 15 para as mulheres, "devendo ser copiado por todos", praticamente tudo o mais na cultura nativa era desprezivel. "Contemplar um desses bárbaros nos dias de sua diplomacia é preparar os olhos para ver um composto de feições o mais horrivel que se pode imaginar", ${ }^{42}$ declarou. Nos rituais festivos, Paula Ribeiro encontra um momento desagradável em que eles "cantam ao som das suas buzinas, maracás e outros instrumentos infernais". ${ }^{43}$

Em suma, apesar de Francisco de Paula Ribeiro ter tido ideias avançadas para seu tempo em relação aos povos

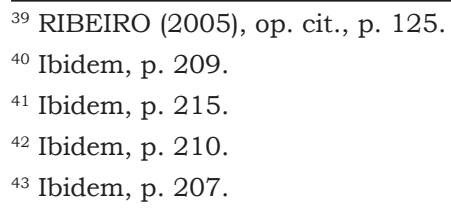


colonizados, pode-se perceber que ele admitia, de maneira sintética, dois tipos de índio: os que estavam propensos à assimilação ao modo de vida do branco e os que eram resistentes a essas propostas. O primeiro foi, na medida do possivel, tolerado, respeitado e até amparado; o segundo, combatido, amedrontado, exterminado se necessário fosse, para o cumprimento do trabalho Real.

\section{Influências do pensamento ribeiriano}

Destacando três dos principais autores da primeira metade do século XX, Parsondas de Carvalho, nos primeiros anos; Carlota Carvalho, cerca de duas décadas mais tarde; e Dunshee de Abranches, mais duas décadas posteriores, percebe-se uma continuação de algumas ideias em relação às percepções deixadas por Francisco de Paula. Essas influências passaram pelo século XX e chegaram ao XXI em trabalhos de historiadores, poetas, compositores e artistas do sertão. Pode-se testificar que as percepções criadoras ribeirianas ainda continuam no pensamento e na escrita de muitos intelectuais.

Parsondas de Carvalho, sertanejo da Chapada, região de Grajaú, conheceu profundamente os sertões maranhenses. Como poeta e jornalista, além de jurista e professor, retratou muito bem as riquezas naturais do lugar e indicou sua potencialidade para a vida sertaneja. Para isso deu um engenhoso enfoque à questão geográfica do sertão.

Disse certa vez que se o pinheiro era a árvore favorita do suíço, para o sertanejo, o mesmo poderia falar-se do bacuri. ${ }^{44}$ Ainda naquela época, demonstrou preocupação com a conservação da paisagem: "o machado do agricultor rotineiro, ignorante, que não conhece nem um dos processos de adubação e fertilização do solo abateu as florestas, e fez desaparecer as nascentes". ${ }^{45}$

${ }^{44}$ CARVALHO APUD DINO, op. cit., p. 140.

${ }^{45}$ Ibidem, p. 120.

230 Revista de História Regional 16(1): 209-234, Verão, 2011 
Contudo, a maior parte da obra de Parsondas é dedicada à sociologia dos conflitos internos do sertão, especialmente ao episódio conhecido por "Guerra dos Leda", conflito dessa família com a de Araújo Costa. O sertão, além de paradisíaco, foi retratado como um lugar de muita violência e desordem. Parsondas tentava combater isso escrevendo em jornais da capital do estado e do país, como o Jornal do Brasil, a fim de chamar a atenção das autoridades.

As mortes, perseguições políticas e ameaças chegaram a tais niveis que, mesmo quando o problema parecia estar-se resolvendo por meio do poder público, a situação regredia e o autor, com certo ceticismo, expressava: "Para mim, nada era porque não conheço, dentro da Constituição de 24 de fevereiro, meio algum para o Governo Federal garantir o cidadão contra a tirania dos governos estaduais". ${ }^{46}$

Carlota Carvalho, referência das mais importantes sobre o sertão maranhense, realiza em sua obra uma densa descrição dos rios sertanejos e de outros elementos paisagísticos. Elabora igualmente uma abordagem social na qual apresenta a fundação de várias povoações importantes e desenha, dentre outras coisas, uma radiografia da vida intelectual do sertão. A autora tenta demonstrar que essa região torna-se abrigo para muitos intelectuais, jornalistas, musicistas e poetas de alto nivel.

Faz uma análise da Balaiada, movimento revolucionário ocorrido nos sertões do Maranhão e liderado por intelectuais e homens pobres, mestiços e vaqueiros. Tem um olhar favorável aos balaios que lutaram por melhores condições de sobrevivência e liberdade política. Para Carlota, nesse período, os melhores espíritos políticos estavam no sertão, para onde vieram perseguidos da capital após a Independência. Eles vieram se esconder nas regiões de Caxias, Chapada, Pastos Bons e tornaram-se grandes lideranças.

Outro trabalho de grande importância para a construção de um olhar sobre o sertão, são as memórias do jurista e político Dunshee de Abranches. Esse vivenciou vários

${ }^{46}$ CARVALHO APUD DINO, op. cit., p. 195. 
acontecimentos políticos no final do século anterior às suas memórias, nas quais relatou alguns deles. Seu trabalho foi assumir a promotoria de Barra do Corda, próxima a Grajaú, com o objetivo maior de observar o intenso conflito existente entre as duas famílias tradicionais do lugar: a família de Araújo Jorge, conservador, e a de Leão Leda, liberal. ${ }^{47}$

Para o promotor do sertão, que morava na Capital, a "Chapada", como era denominada a região de Grajaú, por não ter leis acima do poder de certas famílias, era compreendida como um lugar de violência e decadência.

A Chapada foi "o lugar que recebeu assassinos, ladrões e bandidos" fugidos de outras regiões. ${ }^{48}$ Com o tempo, aderiu ao movimento republicano e a todo um conjunto de valores locais. O sertanejo passou a ter outra imagem: "a alma nobre dos sertões é constituída por uma raça de homens fortes de honra e de espírito forte." ${ }^{99}$

Ao final de seu trabalho investigativo a serviço da Capital sobre os conflitos entre famílias, concluiu que o sertão da Chapada era conflituoso porque o sertanejo era apaixonado pelo seu chão e pela liberdade. O conflito, que era considerado uma esfinge para os administradores de São Luís, foi desvendado: o sertão precisa de leis, mas de suas próprias leis e não as da Capital.

Ele fala da visão que os politicos da capital, inicialmente compartilhada por ele, tinham do sertão: "A idéia que em geral fazem dessa região maravilhosa era falsa, a população desses vales opilada, roída pelas verminoses, devastada cruamente pela malária, não se podia confundir com a gente sã e forte daqueles soberbos planaltos". ${ }^{50}$

Utilizou-se dos exemplos acima para expor como a percepção sobre o sertão foi-se edificando por meio desses intelectuais da primeira metade do século XX, sem fugir das percepções deixadas por Paula Ribeiro. Isso não quer dizer

${ }^{47}$ ABRANCHES, Dunshee de. A Esfinge do Grajaú. Introdução de Jomar Morais. 2. ed. São Luís: Alumar, 1993, p. 152.

${ }^{48}$ Ibidem, p. 99.

${ }^{49}$ Ibidem.

${ }^{50}$ Ibidem, p. 154.

232 Revista de História Regional 16(1): 209-234, Verão, 2011 
que suas impressões foram as únicas ou que esses autores não tiveram seu olhar próprio, diz apenas que houve uma irrefutável influência do militar em relação aos intelectuais posteriores. Isso ocorreu pelo contato direto ou indireto com sua obra, no reforço ou negação de ideias em relação ao sertão e ao sertanejo.

Três elementos evidentes encontram-se na obra de Paula Ribeiro e, em parte, nas obras dos intelectuais do século XX, a respeito dos sertões: a região seria um lugar único em termos paisagísticos; porém ausente do poder público; e que não tem no índio a expressão do lugar, representação que pertence ao vaqueiro.

Resumo: Este texto alude à construção de um olhar sobre os sertões maranhenses, elaborado pelo militar português Francisco de Paula Ribeiro, no limiar do século XIX. Em trabalhos realizados à Corte portuguesa, na instalação de Fazendas Reais e demarcação limítrofe entre as capitanias do Maranhão e Goiás, Paula Ribeiro viajou por todo o sertão e relatou, por meio de suas memórias escritas, aspectos geográficos, econômicos e culturais da região. Esse conjunto de impressões elaborado no decorrer das duas primeiras décadas do século XIX é intitulado aqui de "percepções criadoras". São criadoras no momento em que os principais intelectuais que escreveram sobre os sertões na primeira metade do século XX conservaram parte das impressões ribeirianas, contribuindo para a fixação de imagens, apontando para o abandono e desvalorização do componente humano indígena em prol do vaqueiro.

Palavras chave: Paula Ribeiro. Percepção. Sertão.

Abstract: This text refers to the construction of a glimpse into the hinterlands of the Maranhão state, as formulated by Francisco de Paula Ribeiro, a Portuguese military man, on the threshold of the nineteenth century. While working for the Portuguese court setting up Royal Farms and in the demarcation of boundaries between the neighboring 
captaincies of the Maranhão and Goiás states, Paula Ribeiro traveled throughout the hinterlands and reported, via his written memoirs, the geographic, economical and cultural aspects of the region. This collection of impressions produced during the first two decades of the nineteenth century is referred to in this article as "creative perceptions." They are creative in a period when the main intellectuals who wrote about the hinterlands in the first half of the twentieth century have retained some of the impressions of the riverside population, contributing to the fixation of images, while denouncing the abandonment and devaluation of indigenous human component in favor of the herdsmen.

Keywords: Paula Ribeiro. Perception. Hinterland.

Artigo recebido para publicação em 28/08/2010

Artigo aprovado para publicação em 03/02/2011 